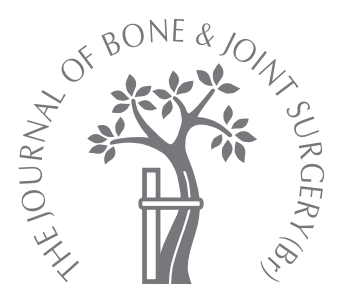

H. Mizu-uchi, S. Matsuda, H. Miura, K. Okazaki, Y. Akasaki, Y. Iwamoto

From Kyushu University, Fukuoka, Japan

\section{The evaluation of post-operative alignment in total knee replacement using a CT-based navigation system}

We compared the alignment of 39 total knee replacements implanted using the conventional alignment guide system with 37 implanted using a CT-based navigation system, performed by a single surgeon. The knees were evaluated using full-length weight-bearing anteroposterior radiographs, lateral radiographs and CT scans.

The mean hip-knee-ankle angle, coronal femoral component angle and coronal tibial component angle were $181.8^{\circ}\left(174.2^{\circ}\right.$ to $\left.188.3^{\circ}\right), 88.5^{\circ}\left(84.0^{\circ}\right.$ to $\left.91.8^{\circ}\right)$ and $89.7^{\circ}\left(86.3^{\circ}\right.$ to $\left.95.1^{\circ}\right)$, respectively for the conventional group and $180.8^{\circ}\left(178.2^{\circ}\right.$ to $\left.185.1^{\circ}\right), 89.3^{\circ}\left(85.8^{\circ}\right.$ to $\left.92.0^{\circ}\right)$ and $89.9^{\circ}\left(88.0^{\circ}\right.$ to $\left.93.0^{\circ}\right)$, respectively for the navigated group.

The mean sagittal femoral component angle was $85.5^{\circ}\left(80.6^{\circ}\right.$ to $\left.92.8^{\circ}\right)$ for the conventional group and $89.6^{\circ}\left(85.5^{\circ}\right.$ to $\left.94.0^{\circ}\right)$ for the navigated group.

The mean rotational femoral and tibial component angles were $-0.7^{\circ}\left(-8.8^{\circ}\right.$ to $\left.9.8^{\circ}\right)$ and $-3.3^{\circ}\left(-16.8^{\circ}\right.$ to $\left.5.8^{\circ}\right)$ for the conventional group and $-0.6^{\circ}\left(-3.5^{\circ}\right.$ to $\left.3.0^{\circ}\right)$ and $0.3^{\circ}\left(-5.3^{\circ}\right.$ to $\left.7.7^{\circ}\right)$ for the navigated group.

The ideal angles of all alignments in the navigated group were obtained at significantly higher rates than in the conventional group. Our results demonstrated significant improvements in component positioning with a CT-based navigation system, especially with respect to rotational alignment.

Total knee replacement (TKR) has become one of the most successful procedures in orthopaedics with survival rates greater than $90 \%$ after 15 years. ${ }^{1,2}$ The success of this procedure depends on many factors, including the preoperative condition of the patient, the design and materials of the components and surgical techniques. ${ }^{1-16}$ It is important to position the femoral and tibial components accurately and to balance the soft tissues. Malpositioning of the component can lead to failures due to aseptic loosening, instability, polyethylene wear and dislocation of the patella. ${ }^{1-14}$

Various surgical techniques and systems of instrumentation have been devised to obtain optimal post-operative alignment of the components. In the coronal plane it is recommended that the femoral and tibial components be positioned with less than $3^{\circ}$ of error, ${ }^{3,4}$ but such placement can only be achieved in $70 \%$ to $80 \%$ of patients using intra- or extramedullary alignment guides.,6 The point of entry of the intramedullary alignment guide is critical as it can change both the coronal and the sagittal alignment. ${ }^{7}$ For rotational alignment of the femoral component, use of the Whiteside line and the transepicon- dylar axis is recommended to avoid problems with the patella. ${ }^{8,9}$ However, the transepicondylar axis can be identified visually within $3^{\circ}$ in only $75 \%$ of arthritic knees ${ }^{17}$ and there may be errors in its identification when using a mini-invasive approach. ${ }^{18}$ We cannot expect a high degree of accuracy using conventional techniques for rotational alignment by palpating anatomical landmarks. ${ }^{17,19,20}$

In order to improve post-operative alignment, navigation systems have been developed for TKR. Many clinical and experimental studies of these systems have shown that the accuracy of implanted components can be improved in spite of the increase in costs and operating time. ${ }^{21-31}$ This may not, however, improve the outcome in the short-term. ${ }^{32}$ Image-free navigation systems estimate the centre of the joint kinematically and digitise the anatomical landmarks. CT-based navigation systems allow three-dimensional preoperative planning from the CT data and surface-matching registration. With both systems, over $90 \%$ of the operated knees achieved alignment of the mechanical axis of the leg within $3^{\circ}$ of neutral, ${ }^{21-26}$ but opinions differ as to the accuracy of image-free systems in 
Table I. The pre-operative demographic data for the conventional and the navigated groups

\begin{tabular}{|c|c|c|}
\hline & Conventional group (39 knees) & Navigated group (37 knees) \\
\hline Mean age in yrs (range) & 76.9 (68 to 85$)$ & 75.4 (61 to 87$)$ \\
\hline \multicolumn{3}{|l|}{ Gender } \\
\hline Male & 8 & 8 \\
\hline Female & 31 & 29 \\
\hline \multicolumn{3}{|l|}{ Diagnosis } \\
\hline Osteoarthritis & 36 & 35 \\
\hline Rheumatoid arthritis & 3 & 2 \\
\hline Pre-operative $\mathrm{KSS}^{*}$ (range) & 54.8 (21 to 76$)$ & $54.4(10$ to 73$)$ \\
\hline Maximum extension $\left({ }^{\circ}\right)$ (range) & $-5.5(-30$ to 0$)$ & $-11.9(-40$ to 0$)$ \\
\hline Maximum flexion $\left({ }^{\circ}\right)$ (range) & $119.4(80$ to 150$)$ & 118.6 (85 to 145$)$ \\
\hline Pre-operative $\mathrm{FTA}^{\dagger}\left({ }^{\circ}\right)$ (range) & $183.8(160.2$ to 194.4$)$ & $181.6(161.0$ to 194.0$)$ \\
\hline Mean follow-up time in yrs (range) & $2.3(0.5$ to 4.7$)$ & $1.8(0.5$ to 4.4$)$ \\
\hline
\end{tabular}

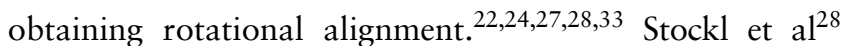
used the post-operative CT scan method and concluded that the image-free navigation systems achieved significantly better rotational alignment of the femoral component than did the conventional group. However, their range of alignment was relatively large $\left(-7^{\circ}\right.$ to $\left.+4^{\circ}\right)$. Siston et $\mathrm{a}^{33}$ found that an image-free navigation system was no more accurate than four traditional techniques in establishing appropriate femoral rotation in ten cadaver specimens. Little information has been published on the rotational alignment of CT-based navigation systems. Registration in a CT-based navigation system uses surface matching of the large aspects of bones, whereas the image-free systems are required to specify anatomical landmarks accurately. We hypothesised that a CTbased system would improve both rotational and coronal alignment. The purpose of this study was to evaluate the accuracy of a CT-based navigation system for TKR in the coronal and rotational planes compared with the use of conventional alignment guides, when employed by a single surgeon.

\section{Patients and Methods}

Of a total of 137 primary TKRs performed in 119 patients by a single surgeon (SM) between January 2002 and January 2006, 81 knees in 68 patients had the Nexgen legacy posterior stabilised prosthesis (Zimmer, Warsaw, Indiana). A conventional alignment guide system and a CT-based navigation system were used in alternate patients. A study of these patients was approved by the Institutional Review Board, and they were informed of the risk of radiation exposure required. Of the 68 patients, informed consent was obtained from 63 (76 knees). A conventional alignment guide system was used in 39 knees in 32 patients (the 'conventional' group), and in 37 knees in 31 patients a CT-based navigation system was used (the 'navigated' group). After operation all patients in both groups were evaluated using full-length weight-bearing anteroposterior and lateral radiographs. All patients in the conventional group and 28 knees in 23 patients in the navigated group were assessed using CT scans. The Knee Society scoring system ${ }^{34}$ was used to evaluate the pre-operative status of the knee one week before the surgery. The demographic data for both groups are presented in Table I; there was little difference between the two groups except for the angle of maximum extension.

Pre-operative planning procedures and surgical technique The conventional group. Full-length weight-bearing anteroposterior radiographs were taken with the patella positioned at the centre of the femoral condyles. In the lateral films care was taken to ensure that the posterior condyles of the femur were not misaligned.

A standard medial parapatellar incision and approach was used. For the distal femur, the intramedullary alignment guide was inserted slightly medial to the midpoint of the femoral condyles. This entry point was determined as the position where the intramedullary line of the femoral canal exits the femoral condyles on the full-length anteroposterior radiographs. The distal femoral cutting block was then attached to the alignment guide and adjusted to the anatomical valgus angle of the femur (mean $5.9^{\circ}, 3.0^{\circ}$ to $\left.9.0^{\circ}\right)$. After cutting the distal femur, the cutting block was set to $3^{\circ}$ of external rotation from the posterior condylar line. The appropriate cuts were then made.

The extramedullary alignment guide was used for cutting the proximal tibia and was set at a level approximately $10 \mathrm{~mm}$ distal to the lateral articular surface of the tibia. The sagittal alignment of the tibia was set parallel to the mechanical axis, and the posterior slope of the tibial component fixed in relation to the lateral tibial plateau. ${ }^{35}$ The rotational alignment of the tibial component was adjusted to the anteroposterior axis between the centre of the cut 


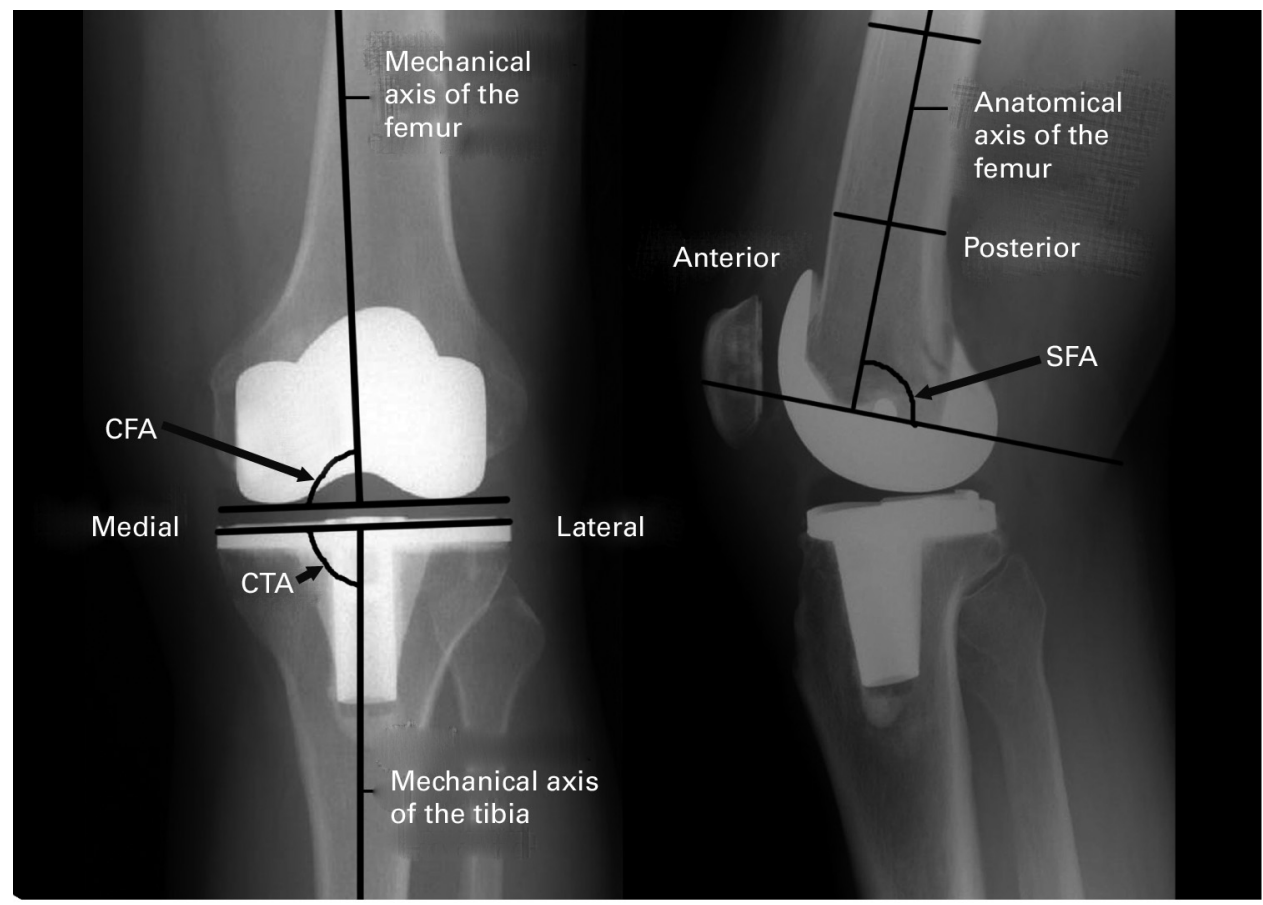

Fig. 1

Evaluation of the coronal and sagittal alignment of the components. The coronal femoral component angle (CFA) is the medial angle between the mechanical axis of the femur and the horizontal axis of the two prosthetic condyles. The coronal tibial component angle (CTA) is the medial angle between the mechanical axis of the tibia and the horizontal axis of the tibial tray. The sagittal femoral component angle (SFA) is the posterior angle between the anatomical axis of the femur and a tangent to the distal part of the femoral component.

surface and the border of the medial third of the tibial tuberosity. ${ }^{36,37}$ This axis was chosen to avoid rotational mismatch of the femoral and tibial components, and to achieve better patellar tracking. ${ }^{10}$ The patella was resurfaced in all patients. All the femoral, tibial and patellar components were fixed with cement.

The navigated group. We used a CT-based navigation system (Vector Vision Knee 1.5. Brain LAB Inc., Heimstetten, Germany). For the initial CT scans, a $100 \mathrm{~mm}$ section of the femoral head, a $200 \mathrm{~mm}$ section whose midpoint was the knee joint and a $100 \mathrm{~mm}$ section of the distal tibia were scanned with a slice thickness of $2 \mathrm{~mm}$. The scanning time was approximately 10 seconds and the calculated radiation dose for the procedure was $3.7 \mathrm{mSV}$. The cost was approximately US\$ 120 to 130 . From these data, we defined the centre of the femoral head and the centre of the ankle joint after adjusting for the bone threshold and the window level and width. The bone threshold value was between $100 \mathrm{HU}$ and $150 \mathrm{HU}$ according to the patient's CT data; the extra artefact was deleted and the bone surface identified as clearly as possible. The femur, tibia and patella were then separated from each other at four points, namely the intercondylar eminence, the lateral tibial plateau, the medial tibial plateau, and the centre of the patella.

The anatomical axis of the femur was defined as the straight line between the centre of the intramedullary canal of the proximal and distal parts of the femur in both the coronal and sagittal planes. The mechanical axis of the femur was taken as the straight line between the centre of the head of the femur and the centre of the distal condyles. The coronal alignment of the femoral component was planned to be perpendicular to the mechanical axis of the femur and the sagittal alignment to be perpendicular to the anatomical axis of the distal femur in order to avoid notching of the femur due to the anterior bowing (mean $3.0^{\circ}$; $1.0^{\circ}$ to $6.0^{\circ}$, in flexion to the mechanical axis). The rotational alignment was adjusted to the surgical epicondylar axis, which is a line connecting the sulcus of the medial epicondyle and the most prominent point of the lateral epicondyle of the femur. ${ }^{8,9}$ After aligning the femoral component to the axis the size of the femoral component was adjusted as close as possible to the posterior condyles. The mechanical axis of the tibia was defined by a straight line between the centre of the cut of the proximal tibia and the centre of the ankle joint. ${ }^{38}$ The planned coronal alignment of the tibial component was perpendicular to this axis. The planned sagittal alignment of the tibial component was parallel to the lateral tibial slope (mean $6.8^{\circ} ; 5.0^{\circ}$ to $8.0^{\circ}$, to the mechanical axis). ${ }^{35}$ The rotational alignment was adjusted to a line from the medial third of the tubercle at the level of the patellar tendon attachment to the centre of the cut surface of the tibia. The tibial component was positioned 


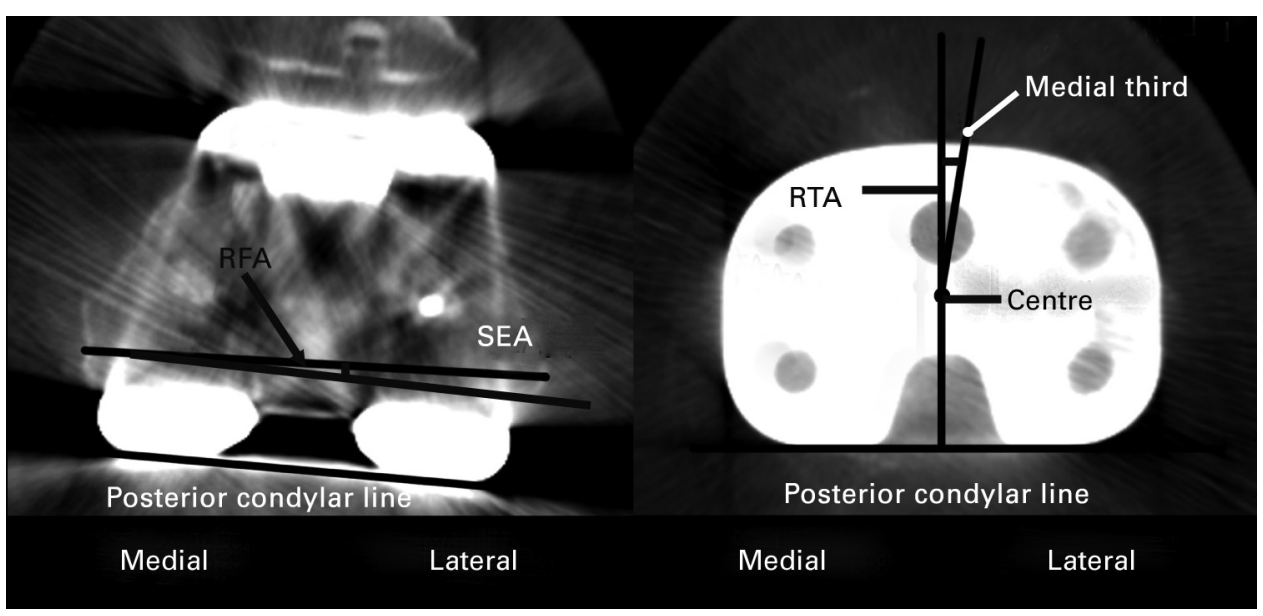

Fig. 2

Evaluation of the rotational alignment of the components. The rotational femoral component angle (RFA) is the angle between the surgical epicondylar axis (SEA) and the posterior condylar line of the femoral component. The rotational tibial component angle (RTA) is the angle between a line connecting the centre of the tibial component with the medial third of the tibial tubercle and the line perpendicular to the posterior condylar line of the tibial component.

Table II. Intra- and inter-observer reliability ( $\kappa$ values)

\begin{tabular}{lll}
\hline & Conventional group (39 knees) & Navigated group (37 knees) \\
\hline $\left.\begin{array}{l}\text { Intra-observer reliability } \\
\begin{array}{l}\text { Intra-observer reliability } \\
\text { (observer A) }\end{array}\end{array}\right) 0.94$ & 0.95 \\
$\begin{array}{l}\text { Intra-observer reliability } \\
\text { (observer B) }\end{array}$ & 0.96 & 0.97 \\
\hline
\end{tabular}

$10 \mathrm{~mm}$ distal from the highest point of the tibial plateau and a size was chosen so that the component would not overhang the medial border of the tibia. The pre-operative planning time was approximately 15 to 20 minutes.

At operation, the same medial parapatellar approach was used as in the conventional group. The reference clamp was fixed to the distal femur or the proximal tibia with one or two pins. Registration using surface matching of the bones was done with a pointer to match the corresponding three-dimensional CT images on the screen. A minimum of eight to a maximum of 20 points were registered until an accuracy of $1.9 \mathrm{~mm}$ or better was achieved. Using the cutting block adapter, the femoral and tibial blocks were positioned to match the plane of cut that had been determined before operation and was shown on the navigation system. After resection, all the planes were checked by the verification tool of the navigation system. The patella was resurfaced in all patients. All the femoral, tibial, and patellar components were fixed with cement.

Evaluation of post-operative alignment. The knees were assessed using the knee and functional score of the Knee Society scoring system six months after operation. Student's $t$-test was used to identify statistically significant differences $(\mathrm{p}<0.05)$.

The alignment in the coronal plane was measured on the anteroposterior whole-leg radiograph (Fig. 1). The mechanical axis of the leg was defined as the hip-kneeankle angle, which is the angle between the line connecting the centre of the hip with that of the knee, the mechanical axis of the femur, and the line connecting the centre of the knee with that of the ankle joint, which is the mechanical axis of the tibia. The ideal hip-knee-ankle angle was defined as within $3^{\circ}$ of $180^{\circ}$. The coronal femoral component angle was measured as the medial angle between the mechanical axis of the femur and the horizontal axis of the two prosthetic condyles. The coronal tibial component angle was measured as the medial angle between the mechanical axis of the tibia and the horizontal axis of the tibial tray. Ideally, both these angles measured within $2^{\circ}$ of $90^{\circ}$.

Alignment in the sagittal plane was measured on lateral radiographs (Fig. 1). The sagittal femoral component angle was defined as the posterior angle between the anatomical axis of the distal one-third of the femur and a tangent to the distal part of the femoral component. The tangent was 
Table III. The differences of absolute value from the target angle $\left({ }^{\circ}\right)$

\begin{tabular}{llll}
\hline & Target angle & Conventional group & Navigated group \\
\hline Hip-knee-ankle angle $\left({ }^{\circ}\right.$; range) & 180 & $2.7(0$ to 8.3$)$ & $1.4(0$ to 5.1$)$ \\
Coronal femoral component angle $\left({ }^{\circ} ;\right.$ range $)$ & 90 & $2.2(1$ to 6.0$)$ & $1.3(0$ to 4.2$)$ \\
Coronal tibial component angle $\left(^{\circ}\right.$ range $)$ & 90 & $1.5(0.2$ to 5.1$)$ & $1.1(0$ to 3.0$)$ \\
Sagittal femoral component angle $\left({ }^{\circ}\right.$; range $)$ & 90 & $4.7(0.7$ to 9.4$)$ & $1.5(0$ to 4.6$)$ \\
Rotational femoral component angle $\left({ }^{\circ} ;\right.$ range) & 0 & $2.7(0.1$ to 9.8$)$ & $1.6(0.4$ to 3.5$)$ \\
Rotational tibial component angle $\left({ }^{\circ} ;\right.$ range $)$ & 0 & $4.8(0$ to 16.8$)$ & $2.5(0$ to 7.7$)$ \\
\hline
\end{tabular}

treated to be parallel to the bone-implant interface of the distal part of the femoral component. The ideal angle lay within $3^{\circ}$ of $90^{\circ}$.

Rotational alignment was measured on the CT scan (Fig. 2). A $200 \mathrm{~mm}$ section whose midpoint was the knee joint only was scanned with a slice thickness of $2 \mathrm{~mm}$. The rotational femoral component angle was defined as the angle between the surgical epicondylar axis and the posterior condylar line of the femoral component. The rotational tibial component angle was defined as the angle between a line connecting the centre of the tibial component and the medial third of the tibial tubercle and a line perpendicular to the posterior condylar line of the tibial component. The ideal femoral component and rotational tibial angles are defined as within $3^{\circ}$ of the target angle $\left(0^{\circ}\right) .{ }^{17,27}$

Statistical analysis. A Mann-Whitney U test was used to determine statistically significant differences $(p<0.05)$ in absolute value from the target angles between the two systems using these parameters. Fisher's exact probability test was used to compare the quality of implantation, measured against the ideal position, between the two systems with these parameters $(\mathrm{p}<0.05)$. In addition, we evaluated a correlation between error in rotational alignment and the functional score for both groups using Spearman's correlation coefficient by rank test $(\mathrm{p}<0.05)$. All measurements were done by two observers (HM and YA). The blinded data did not include the patient information and were numbered randomly. The mean values of three measurements using a digital X-ray measuring system (X-caliper; Eisenlohr Technologies Inc., Davis, California) were measured. The chance-corrected $\kappa$-coefficient was calculated to determine intra- and inter-observer agreement, with $\kappa$ values interpreted according to the recommendations of Landis and Koch. ${ }^{39}$ Intra- and interobserver reliability were almost perfect $(\mathrm{p}<0.001$ in each case, Table II).

\section{Results}

The mean post-operative Knee Society score was $94.9(62$ to 100) for the conventional and 95.0 (70 to 100) for the navigated group. The mean post-operative functional score was 78.1 (5 to 100) for the conventional group and 78.2 (30 to 100) for the navigated group. No significant difference was detected in these values for the two groups. No patients had a flexion contracture of more than $20^{\circ}$ or a flexion angle of less than $90^{\circ}$ at six months after surgery.
For coronal alignment, the mean hip-knee-ankle angle was $181.8^{\circ}\left(174.2^{\circ}\right.$ to $\left.188.3^{\circ}\right)$ for the conventional and $180.8^{\circ}$ $\left(178.2^{\circ}\right.$ to $\left.185.1^{\circ}\right)$ for the navigated group. The mean coronal femoral component angle was $88.5^{\circ}\left(84.0^{\circ}\right.$ to $\left.91.8^{\circ}\right)$ for the conventional and $89.3^{\circ}\left(85.8^{\circ}\right.$ to $\left.92.0^{\circ}\right)$ for the navigated group. The mean coronal tibial component angle was $89.7^{\circ}\left(86.3^{\circ}\right.$ to $\left.95.1^{\circ}\right)$ for the conventional and $89.9^{\circ}\left(88.0^{\circ}\right.$ to $93.0^{\circ}$ ) for the navigated group. The differences in absolute value from the target angle are shown in Table III. There were significant differences in the absolute values from the target angle in tests for the hip-knee-ankle angle ( $\mathrm{p}$ $<0.01)$ and the coronal femoral component angle ( $\mathrm{p}=$ 0.02 ), but no significant difference in the coronal tibial component angle $(\mathrm{p}=0.24)$ between the two groups. Ideal hip-knee-ankle, coronal femoral component, and coronal tibial component angles were obtained in $71.8 \%$ (28 of 39 knees), $71.8 \%$ (28 of 39 knees), and $76.9 \%$ (30 of 39 knees) of operations for the conventional group, and $91.9 \%$ (34 of 37 knees), $91.9 \%$ (34 of 37 knees), and $94.6 \%$ (35 of 37 knees) of operations for the navigated group ( $\mathrm{p}<0.05, \mathrm{p}<0.05, \mathrm{p}<0.05)$, respectively.

For sagittal alignment, the mean sagittal femoral component angle was $85.5^{\circ}\left(80.6^{\circ}\right.$ to $\left.92.8^{\circ}\right)$ for the conventional and $89.6^{\circ}\left(85.4^{\circ}\right.$ to $\left.94.0^{\circ}\right)$ for the navigated group. There was a significant difference in the absolute values from the target angle of the sagittal femoral component angle $(\mathrm{p}<0.0001)$ between the two groups. Ideal sagittal femoral component angles were obtained in $43.6 \%$ (17 of 39 knees) in the conventional group and $89.2 \%$ (33 of 37 knees) in the navigated group $(\mathrm{p}<0.01)$.

For rotational alignment, the mean rotational femoral component angle was $-0.7^{\circ}\left(-8.8^{\circ}\right.$ to $\left.9.8^{\circ}\right)$ for the conventional and $-0.6^{\circ}\left(-3.5^{\circ}\right.$ to $\left.3.0^{\circ}\right)$ for the navigated group. The mean rotational tibial component angle was $-3.3^{\circ}\left(-16.8^{\circ}\right.$ to $\left.5.8^{\circ}\right)$ for the conventional and $0.3^{\circ}\left(-5.3^{\circ}\right.$ to $\left.7.7^{\circ}\right)$ for the navigated group. There was a significant difference in the absolute values from the target angle of the rotational femoral component $(p=0.04)$ and rotational tibial component angles $(\mathrm{p}=0.03)$ between the two groups. Ideal rotational femoral component and rotational tibial component angles were obtained in $66.7 \%$ ( 26 of 39 knees) and $46.2 \%$ (18 of 39 knees) in the conventional group and $89.3 \%$ ( 25 of 28 knees) and $78.6 \%$ (22 of 28 knees) in the navigated group $(\mathrm{p}=0.04$ and 0.01$)$, respectively. There was no significant correlation between errors in rotational alignment and 
the functional score for both the femoral and the tibial components.

\section{Discussion}

Total knee replacement has become a very successful procedure owing to improvements in prostheses and in surgical techniques. However, malpositioning of the components may occur when the conventional method is used. ${ }^{1-14}$ Longleg standing radiographs are commonly used for preoperative planning, but they can be affected by the position of the limb and the direction of scanning because they are two-dimensional images. Other possible causes of error include bowing of the bones, severe deformities and obesity.

Navigation systems for TKR have been developed to reduce these errors. This study compared post-operative alignment achieved using CT-based navigation with that using the conventional system. For coronal alignment, the positioning of components was improved by the navigation system, with results similar to those of Nizard et $\mathrm{al}^{25}$ and Perlick et al. ${ }^{26}$ The CT-based system ensures the accuracy of positioning the components in the coronal plane.

The sagittal alignment of the components was improved by the navigation system. Poorer results with the conventional method seem to relate to the use of the intramedullary guide whose alignment is affected by its point of entry and direction. Mihalko et $\mathrm{al}^{7}$ found differences in alignment in the sagittal plane using three different entry points for the intramedullary guide. Their trials on seven cadaver limbs varied between $2.2^{\circ}$ of extension and $3.8^{\circ}$ of flexion relative to the mechanical axis. With the image-free navigation system, many authors have concluded that this method is useful for cutting the distal femur perpendicular to the mechanical axis of the femur. ${ }^{28}$ However, this method may increase the risk of notching the anterior cortex of the distal femur and require manual adjustment of the position of the cutting guide to avoid this. We chose the anatomical axis of the distal femur as the planned sagittal alignment of the femoral component to avoid notching. Post-operative sagittal alignment was also measured using the distal anatomical axis as a reference line to minimise the effect of sagittal bowing of the femur.

Few studies have yet demonstrated any advantages of the CT-based navigation system with respect to rotational alignment. In our series, $89.3 \%$ of the femoral components were implanted within $3^{\circ}$ of the ideal rotational alignment and the range $\left(-3.5^{\circ}\right.$ to $\left.3.0^{\circ}\right)$ was relatively small. Using the image-free system, it is uncertain whether digitising the bony landmarks is precise, and the accuracy of the rota-

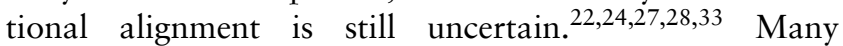
authors ${ }^{17,19,20}$ have reported variability in the identification of the transepicondylar axis. Yau et ${ }^{19}$ found that the maximum combined error was $8.2^{\circ}$, with $5.3^{\circ}$ at the medial femoral epicondyle and $2.9^{\circ}$ at the lateral in the transepicondylar axis. These results suggest that surgeons are not able to rely completely on the accuracy of the imagefree navigation system. Image-free systems are more widely used than the CT-based system, probably because of the need for pre-operative CT scans and the planning time.

Although this study has shown that the CT-based navigation system significantly improved the accuracy of the rotational alignment of the tibial component, the variation from the ideal angle of tibial alignment was larger than that of the femoral alignment, as others have noted..$^{22,24,27}$ One reason for this is the difficulty in determining the medial third of the tibial tubercle at the same point as was defined pre-operatively. Even so, $78.6 \%$ of the tibial components in the navigated group were implanted within $3^{\circ}$ of the ideal rotational alignment, as has been found using an image-free navigation system. ${ }^{22}$

It is difficult to determine the ideal tibial rotational alignment because the method of defining the anteroposterior axis of the tibia is variable. ${ }^{36,37}$ We used the line connecting the centre of the tibia and the medial third of the tibial tubercle as the reference axis to avoid the rotational mismatch between the femoral and tibial components ${ }^{36,37}$ and to achieve better patellar tracking. ${ }^{10}$

Determining the indicator of 'outliers' is another difficult issue in tibial rotational alignment. Rotator restraint produced by the tibiofemoral linkage of the posterior stabilised design should be considered. However, the Nexgen legacy posterior stabilised prosthesis (Zimmer) has $12^{\circ}$ of freedom of internal and external rotation in full extension. In this study, within $3^{\circ}$ was chosen for the ideal range in order to be able to compare the accuracy with other navigation systems. ${ }^{27}$

Some reports ${ }^{21,29}$ comparing the accuracy of the CTbased navigation system to that of the image-free navigation system show no differences in the accuracy of the postoperative alignment using the radiographs. Image-free navigation systems are widely used for computer-assisted surgery. Jenny et $\mathrm{al}^{23}$ reported that $92.3 \%$ (217 of 235 knees) of operations had a coronal mechanical femorotibial angle within a range of $\pm 3^{\circ}$ using the OrthoPilot system (Aesculap, Tuttlingen, Germany), compared with $72.3 \%$ (170 of 235 knees) with conventional methods. Tingart et $\mathrm{al}^{30}$ reported that $94.8 \%$ (474 of 500 knees) of operations had a varus/valgus alignment within a range of $\pm 3^{\circ}$ of $180^{\circ}$ (the target angle of the mechanical axis) using the VectorVision CT-free Knee (BrainLAB, Munich, Germany; CI System Orthopedics, Munich, Germany), compared with $74.4 \%$ (372 of 500 knees) with conventional methods. The main disadvantage of the CT-based navigation system is that it requires pre-operative preparation with additional costs and exposure to radiation. However, our results show that the CT-based system has advantages over the imagefree system, in particular in determining femoral rotation.

The current study has some limitations. The number of patients is relatively small. The post-operative alignment was evaluated by radiographs and/or CT images. This is a two-dimensional evaluation and is affected by the positioning of the limb and the direction of scanning, despite the fact that pre-operative planning and intra-operative procedures are performed in three dimensions. Cobb et $\mathrm{al}^{40}$ 
reported the accuracy of unicompartmental knee replacement three-dimensionally from the pre-operative and postoperative CT images. It is important to evaluate the postoperative alignment three-dimensionally. However, our post-operative CT was performed only around the knee joint, in order to minimise the dose of radiation, and wholeleg alignment was evaluated by this method. The sagittal alignment of the tibial component was not evaluated as it was adjusted to the lateral anatomical tibial slope.

This study evaluated the accuracy of a CT-based navigation system using post-operative radiographs and CT scans. Our results demonstrate significant improvements in positioning of the components with the CT-based system, especially with respect to rotational alignment.

The authors wish to thank S Hamai, and S Fukagawa, Department of Orthopaedic Surgery Graduate School of Medical Sciences, Kyushu University, Fukuoka, Japan, for help in the blinded post-operative assessment.

No benefits in any form have been received or will be received from a commercial party related directly or indirectly to the subject of this article.

\section{References}

1. Rodricks DJ, Patil S, Pulido P, Colwell CW Jr. Press-fit condylar design total knee arthroplasty: fourteen to seventeen-year follow-up. J Bone Joint Surg [Am] 2007;89-A:89-95

2. Vessely MB, Whaley AL, Harmsen WS, Schleck CD, Berry DJ. Long-term survivorship and failure modes of 1000 cemented condylar total knee arthroplasties. Clin Orthop 2006; 452:28-34.

3. Jeffery RS, Morris RW, Denham RA. Coronal alignment after total knee replacement. J Bone Joint Surg [Br] 1991;73-B:709-14.

4. Rand JA, Coventry MB. Ten-year evaluation of geometric total knee arthroplasty Clin Orthop 1988;232:168-73.

5. Mahaluxmivala J, Bankes MJ, Nicolai P, Aldam CH, Allen PW. The effect of surgeon experience on component positioning in 673 Press Fit Condylar posterior cruciate-sacrificing total knee arthroplasties. J Arthroplasty 2001;16:635-40.

6. Petersen TL, Engh GA. Radiographic assessment of knee alignment after total knee arthroplasty. J Arthroplasty 1988;3:67-72.

7. Mihalko WM, Boyle J, Clark LD, Krackow KA. The variability of intramedullary alignment of the femoral component during total knee arthroplasty. J Arthroplasty 2005;20:25-8.

8. Berger RA, Rubash HE, Seel MJ, Thompson WH, Crossett LS. Determining the rotational alignment of the femoral component in total knee arthroplasty using the epicondylar axis. Clin Orthop 1993;286:40-7.

9. Matsuda S, Miura H, Nagamine R, et al. A comparison of rotational landmarks in the distal femur and the tibial shaft. Clin Orthop 2003;414:183-8.

10. Berger RA, Crossett LS, Jacobs JJ, Rubash HE. Malrotation causing patellofemoral complications after total knee arthroplasty. Clin Orthop 1998;356:144-53.

11. D'Lima DJ, Patil S, Steklov N, Colwell CW Jr. Dynamic intraoperative ligament balancing for total knee arthroplasty. Clin Orthop 2007;463:208-12.

12. Griffin WL, Fehring TK, Pomeroy DL, Gruen TA, Murphy JA. Sterilization and wear-related failure in first- and second-generation press-fit condylar total knee arthroplasty. Clin Orthop 2007;464:16-20.

13. Noble PC, Conditt MA, Cook KF, Mathis KB. Patient expectations affect satisfaction with total knee arthroplasty. Clin Orthop 2006;452:35-43.

14. Walker PS, Yildirim G, Sussman-Fort J, et al. Factors affecting the impingement angle of fixed- and mobile-bearing total knee replacements: a laboratory study. $J$ Arthroplasty 2007;22:745-52.

15. Epinette JA, Manley MT. Hydroxyapatite-coated total knee replacement: clinical experience at 10 to 15 years. J Bone Joint Surg [Br] 2007;89-B:34-8.

16. Tai CC, Cross MJ. Five- to 12-year follow-up of a hydroxyapatite-coated cementless total knee replacement in young, active patients. J Bone Joint Surg $[B r] 2006 ; 88$ B:1158-63

17. Kinzel V, Ledger $\mathbf{M}$, Shakespeare $\mathbf{D}$. Can the epicondylar axis be defined accurately in total knee arthroplasty? Knee 2005;12:293-6.
18. Yau WP, Leung A, Liu KG, et al. Errors in the identification of the transepicondylar and anteroposterior axes of the distal femur in total knee replacement using minimally-invasive and conventional approaches: a cadaver study. J Bone Joint Surg [Br] 2008:90-B:520-6.

19. Yau WP, Leung A, Chiu KY, Tang WM, Ng TP. Intraobserver errors in obtaining visually selected anatomic landmarks during registration process in non image-based navigation-assisted total knee arthroplasty: a cadaveric experiment. J Arthroplasty 2005;20:591-601.

20. Jenny JY, Boeri C. Low reproducibility of the intra-operative measurement of the transepicondylar axis during total knee replacement. Acta Orthop Scand 2004;75:74-

21. Bathis H, Perlick L, Tingart M, et al. Radiological results of image-based and nonimage-based computer-assisted total knee arthroplasty. Int Orthop 2004;28:87-90.

22. Chauhan SK, Scott RG, BreidahI W, Beaver RJ. Computer-assisted knee arthroplasty versus a conventional jig-based technique: a randomised, prospective trial. $J$ Bone Joint Surg [Br] 2004;86-B:372-7.

23. Jenny JY, Clemens U, Kohler S, et al. Consistency of implantation of a total knee arthroplasty with a non-image-based navigation system: a case-control study of 235 cases compared with 235 conventionally implanted prostheses. J Arthroplasty 2005;20:832-9.

24. Matziolis G, Krocker D, Weiss U, Tohtz S, Perka C. A prospective, randomized study of computer-assisted and conventional total knee arthroplasty: three-dimensional evaluation of implant alignment and rotation. J Bone Joint Surg [Am]2007;89A:236-43.

25. Nizard RS, Porcher R, Ravaud P, et al. Use of the Cusum technique for evaluation of a CT-based navigation system for total knee replacement. Clin Orthop 2004:425:180-8.

26. Perlick L, Bathis H, Tingart M, Perlick C, Grifka J. Navigation in total-knee arthroplasty: CT-based implantation compared with the conventional technique. Acta Orthop Scand 2004;75:464-70.

27. Kim YH, Kim JS, Yoon SH. Alignment and orientation of the components in total knee replacement with and without navigation support: a prospective, randomised study. J Bone Joint Surg [Br] 2007;89-B:471-6.

28. Stockl B, Nogler M, Rosiek R, et al. Navigation improves accuracy of rotational alignment in total knee arthroplasty. Clin Orthop 2004;426:180-6.

29. Martin A, von Strempel A. Two-year outcomes of computed tomography-based and computed tomography free navigation for total knee arthroplasties. Clin Orthop 2006;:449:275-82.

30. Tingart $\mathbf{M}$, Luring $\mathbf{C}$, Bathis $\mathbf{H}$, et al. Computer-assisted total knee arthroplasty versus the conventional technique: how precise is navigation in clinical routine? Knee Surg Sports Traumatol Arthrosc 2008; 16:44-50.

31. Nabeyama R, Matsuda S, Miura H, et al. The accuracy of image-guided knee replacement based on computed tomography. J Bone Joint Surg [Br]2004;86-B:366-71.

32. Spencer JM, Chauhan SK, Sloan K, Taylor A, Beaver RJ. Computer-navigation versus conventional total knee replacement: no difference in functional results at two years. J Bone Joint Surg [Br] 2007;89-B:477-80.

33. Siston RA, Patel JJ, Goodman SB, Delp SL, Giori NJ. The variability of femoral rotational alignment in total knee arthroplasty. J Bone Joint Surg [Am] 2005;87A:2276-80.

34. Insall JN, Dorr LD, Scott RD, Scott WN. Rationale of the Knee Society clinical rating system. Clin Orthop 1989:248:13-14.

35. Kuwano T, Urabe K, Miura $\mathbf{H}$, et al. Importance of the lateral anatomic tibial slope as a guide to the tibial cut in total knee arthroplasty in Japanese patients. J Orthop Sci 2005; 10:42-7.

36. Matsui Y, Kadoya Y, Uehara K, Kobayashi A, Takaoka K. Rotational deformity in varus osteoarthritis of the knee: analysis with computed tomography. Clin Orthop 2005;433:147-51.

37. Mizu-uchi H, Matsuda S, Miura H, et al. The effect of ankle rotation on cutting of the tibia in total knee arthroplasty. J Bone Joint Surg [Am] 2006;88-A:2632-6.

38. Matsuda S, Mizu-uchi H, Miura H, et al. Tibial shaft axis does not always serve as a correct coronal landmark in total knee arthroplasty for varus knees. J Arthroplasty 2003:18:56-62.

39. Landis JR, Koch GG. The measurement of observer agreement for categorical data. Biometrics 1977:33:159-74.

40. Cobb J, Henckel J, Gomes $\mathbf{P}$, et al. Hands-on robotic unicompartmental knee replacement: a prospective, randomised controlled study of the acrobot system. $J$ Bone Joint Surg [Br] 2006;88-B:188-97. 